\title{
La no-ciudad posmoderna en El Jardí del Set Crepuscles de Miquel de Palol
}

\author{
Chiara GIORDANO \\ Doctorado en Estudios Literarios \\ Universidad Complutense de Madrid \\ chiaragi@ucm.es
}

Recibido: $14 / 09 / 2015$

Modificado: $10 / 01 / 2016$

Aceptado: 05/02/2016

\section{Resumen}

El Jardí del Set Crepuscles -primera novela del escritor y arquitecto catalán Miquel de Palol- nos brinda la oportunidad de reflexionar acerca de la metamorfosis experimentada por la ciudad occidental a principios de los años setenta del siglo pasado. De acuerdo con autores como Henri Lefebvre, David Harvey, Giandomenico Amendola o Edward Soja, el surgimiento de la ciudad posmoderna en el marco de la transición hacia el modo de acumulación postfordista se presenta acompañado por un debilitamiento del tejido social y de la esfera pública y cívica. El objetivo del presente artículo es ilustrar las estrategias narrativas y retóricas con las que el texto de Miquel de Palol representa, y analiza, dicho fenómeno.

Palabras clave: El Jardí del Set Crepuscles, posmodernidad, postfordismo, ciudad, crítica de la ideología.

Title: The Postmodern Non-city in Miquel de Palol's El Jardí del Set Crepuscles

\section{Abstract}

El Jardí del Set Crepuscles -the first novel of Catalan writer and architect Miquel de Palol- gives us the opportunity to reflect on the metamorphosis of western cities in the early seventies of the last century. According to authors such as Henri Lefebvre, David Harvey, Giandomenico Amendola or Edward Soja, the emergence of the postmodern city during the transition to the post-Fordist regime of accumulation occurs accompanied by a weakening of the public sphere. The objective of this paper is to illustrate the narrative and rhetorical strategies used by Miquel de Palol to represent and analyze this transformation.

Keywords: El Jardí del Set Crepuscles, postmodernity, post-fordism, city, ideological criticism.

\section{Índice}

1. Introducción

2. La ciudad, una inmensa bolsa de pus

3. De la ciudad postapocalíptica a la no-ciudad posmoderna

4. Otros espacios, espacios privados: el jardín y el palacio

5. A modo de conclusión 


\section{Introducción}

El objetivo del presente artículo es rastrear las huellas de un fantasma entre las páginas de la que probablemente es una de las novelas más singulares y desmesuradas de la posmodernidad peninsular. La novela a la que nos referimos es El Jardí dels Set Crepuscles, primera incursión en la narrativa del escritor catalán Miquel de Palol, originalmente publicada en tres entregas en $1989^{1}$. El fantasma que perseguimos es la ciudad, considerada como eje narrativo espacial -espacio en el que, como veremos, no se mueven los personajes, expulsados de la vida urbana a raíz de una alarma atómica- y como punto de partida para la identificación de un ideologema textual; es decir, de un sema ideológico postulado por el propio texto y expresivo de una situación histórico-social concreta: el debilitamiento del tejido social y de la esfera pública en la ciudad posmoderna y postfordista ${ }^{2}$. En ambos casos, esta se definirá por negación: ciudad postapocalíptica, no-ciudad, espacio privado.

Evidentemente, al elegir un objeto de estudio tan concreto esto es, las estrategias retóricas y narrativas mediante las cuales la novela de Miquel de Palol representa y analiza la ciudad posmoderna en el marco de la transición hacia el modo de acumulación postfordista- y al enfocar el discurso desde el punto de vista de los estudios sobre la ciudad, necesarios para complementar el análisis más propiamente textual ${ }^{3}$, nos vemos obligados a descartar otros caminos que el texto, a lo largo de sus ochocientas páginas, invita a recorrer. Con El Jardí dels Set Crepuscles, Miquel de Palol suspende, aunque solo momentáneamente, una prolífica actividad poética empezada en 1972 y entra en el mundo de la narrativa posmoderna adoptando todas las reglas del juego. De dimensiones pynchonianas y

${ }^{1}$ La bibliografía sobre el poeta, novelista y arquitecto catalán Miquel de Palol es aún escasa. Entre los pocos estudios críticos disponibles, destacamos La ciutat interrompuda de Julià Guillamon (2001), El fin de la sospecha. Calas significativas en la narrativa española (1993-2003) de Ángel García Galiano (2004), un monográfico incluido en el volumen 39 de la revista valenciana Carácters (2007) y el más reciente Narrativa catalana de la postmodernitat de Jordi Marrugat (2014). Todos los autores mencionados coinciden en considerar las novelas de Miquel de Palol como representativas de la poética posmoderna.

2 Para el uso del concepto de "ideologema" en el ámbito de la presente investigación remito al conocido texto de Fredric Jameson de 1981, The Political Unconscious. En él, el estudioso norteamericano reformula, a la luz de las aportaciones de la crítica de la ideología, la definición semiótica de "ideologema" dada por Julia Kristeva, describiéndolo como "the smallest intelligible unit of the essentially antagonistic collective discourses of social classes" (Jameson 2002: 61).

3 De especial modo, nos apoyaremos en los estudios de autores como Henri Lefebvre, David Harvey, Giandomenico Amendola y Edward Soja y, más en general, en los conceptos proporcionados por la arquitectura y el urbanismo crítico y por la crítica ideológica de la ciudad. 
empedrada de referencias intertextuales y metaliterarias ${ }^{4}$, la novela se presenta al lector como un manuscrito encontrado por Miquel de Palol i Moholy-McCullidylly, erudito bibliotecario del cuarto milenio e irónico prologuista del texto. El manuscrito consta de tres partes Frixus el boig, Googol y La joia retrobada- y relata en primera persona los hechos que siguen al estallido de la primera guerra nuclear de la Edad Contemporánea: estamos alrededor del año 2025 y los países hegemónicos se están convirtiendo en desiertos inhabitables, en hecatombes. Con el objetivo de sobrevivir y salvaguardar sus privilegios, las élites económicas y políticas de Occidente buscan amparo en un refugio nuclear secreto, el Palau de la Muntanya. Ahí, los protagonistas de la novela (todos ellos, banqueros -o hijos de-, comerciantes, economistas, ministros de finanzas) se dedican a lo largo de seis días a contar historias y a disfrutar del lujo y la seguridad de la mansión, sin por ello dejar de ejercitar su poderosa influencia (esencialmente económica) sobre el desarrollo de la guerra. Los relatos de la primera y la última parte del Jardí (Frixus el boig y La joia retrobada) gravitan alrededor del Banco Mir y de la familia que lo controla, y reconstruyen las vicisitudes de una joya de naturaleza misteriosa, causa oculta del estallido del conflicto. Googol, en cambio, cubre las dos jornadas centrales y se presenta como un vertiginoso laberinto estructural: los relatos encajan uno dentro de otro en un juego de mise en abyme que llega a constituir hasta ocho niveles narrativos. Más allá del círculo vicioso en que parecen caer los narradores -el llamado reflejo paradójico (Dällenbach 1991)-, es posible detectar una compleja red de simetrías y reenvíos semánticos. Las historias narradas, observa Julià Guillamon,

no són altra cosa que el reflex i l'expressió material de la dialèctica de la reunió. [...] Els narradors pretenen comunicar el seu missatge mitjançant símbols, de manera que la història no és altra cosa que una imatge al servei dels diferents interessos en joc. (Guillamon 2001: 131, 132)

La séptima y última jornada tiene la función de atar cabos sueltos y desvelar tanto el auténtico propósito de la reunión -crear y

4 Referencias que van desde la evidente intertextualidad estructural con el Decamerón y Las mil y una noches y la paratextualidad con el Manuscrit trouvé à Saragosse y Borges, hasta un catálogo amplísimo de citas e intertextualidades puntuales (Shakespeare, la mitología antigua -tanto clásica como bíblica-, Calderón, etc.), a las cuales hay que añadir mecanismos de intertextualidad genérica. En el Jardí (especialmente en los relatos del segundo libro), el autor se aventura en todo tipo de géneros, subgéneros y modalidades: novela de ciencia ficción, relato autobiográfico, roman à clef, novela de aventuras, bildungsroman, novela filosófica, metaliteratura, poesía, ensayo. 
entrenar una "aristocràcia de sang" (Guillamon 2001: 132), nueva élite dominante de una sociedad por reconstruir- como el papel reservado al desorientado narrador principal.

\title{
2. La ciudad, una inmensa bolsa de pus
}

La novela se abre sobre un escenario que nos sitúa, desde la primera página, en el núcleo del tema que nos atañe. Cuenta el narrador:

\begin{abstract}
Barcelona, en la primera alarma atòmica de la seva història, era I'hecatombe. A part el pànic i la incredulitat, el que més meravellava els qui, com jo, podien permetre's una meditació, era com la vida de la ciutat i del país, l'organització i l'ordre, les vies dels costums, allò que quan tot va bé es veu com obligacions a suportar, s'havien enfosat en un parell de dies, como si haguéssim viscut sota una immensa bossa de pus que tan sols espera una punció per rebentar. Dos fenòmens inversos eren els principals causants del caos. D'una banda, l'allau famolenca i ensangonada de francesos [...] supervivents dels seus països $[. .$.$] ; d'altra banda, la dèria$ esbojarrada i sovint suïcida dels barcelonins per abandonar la ciutat [...]. En dos dies, les sortides naturals de l'àrea urbana continuaven abarrotades de frustrats fugitius, però la majoria de la població s'havia desenganyat de les possibilitats de supervivència, i la ciutat era en mans dels estrangers, de la gent sense recursos i dels desesperats. [...] Imperava la llei de la selva; bandes fosques, armades de cap a peus, circulaven entre pilots de runa i porqueria. A les nits tot eren tenebres; I'única llum la feien les fogueres de les places i la d'algun edifici on s'havia calat foc [...]. L'exèrcit va intentar controlar la situació, però aviat les patrulles van ser víctimes de la corrupció, i van caure en la mateixa conducta que les bandes que havien de combatre. (Palol 1996: 3)
\end{abstract}

Como se puede apreciar, la descripción no se aleja de los códigos propios de la ficción ( $y$, en especial modo, de la ciudad) postapocalíptica: una ciudadanía desordenada y en estado de pánico obstruye las vías de huida, el estado de derecho queda suspendido (dejando la ciudad presa de la corrupción y la delincuencia), las infraestructuras han dejado de funcionar y el paisaje urbano está dominado por escombros, hogueras y cadáveres. Sin embargo, desde las primeras líneas, destaca la actitud fría y distante del narrador. Ante la hecatombe, como él mismo la define, el joven protagonista del Jardí deja a un lado -literalmente, pone aparte, y por lo tanto excluye y decide ignorar- el pánico y la incredulidad. Ante el derrumbamiento de su propia ciudad, el narrador, sencillamente, se maravilla.

Como intentaremos aclarar a lo largo de esta contribución, desde el punto de vista del narrador, lo que acaba de reventar no es una ciudad entendida como el espacio de una ciudadanía, sino un sistema de obligaciones. El inminente desastre nuclear no hace otra 
cosa que poner de manifiesto la enfermedad que afecta al organismociudad y la precariedad de su organización: Barcelona es una inmensa bolsa de pus que, por fin, acaba de reventar.

Ahora bien, para diagnosticar la enfermedad que padece la ciudad e interpretar la actitud del narrador, es necesario buscar en el texto otras representaciones del espacio urbano. El segundo relato del Jardí -"Història de Lluïsa Cros"- se abre con el regreso a Barcelona de Alexis Cros, director de la sucursal iberoamericana del banco Mir y sucesivamente su accionista único:

Al seu retorn, Alexis Cros va trobar un país totalment venut. El turisme, en d'altres èpoques una de les fonts principals de divises, pràcticament havia desaparegut després de la paulatina degradació producte d'un insensat i caòtic procés de negoci fàcil, i consegüent malvenda de l'ànima col-lectiva, que havia convertit els paratges més atractius en suburbis abominables. (Palol 1996: 34)

El mismo proceso de decadencia imparable lo percibe Patrici Ficinus en el tercer relato de la novela, contenido en "Història de Lluïsa Cros" y narrado en primera persona por el propio Ficinus:

Com tots sabeu, quan jo era estudiant (és a dir, ara deu fer uns quinze anys), les Rambles i la part baixa de Barcelona eren una cosa molt diferent del que és ara. Els vells d'aleshores ja ho trobaven arruïnat en relació a la seva joventut; pel que jo he vist, i per tal com ara està tot plegat, us puc assegurar que el degenerament i la destrucció han crescut en progressió geomètrica. (Palol 1996: 42)

Cuando Ficinus regresa a Barcelona, solo seis años después, se encuentra con un panorama incluso peor: Barcelona se ha convertido en una ciudad inhóspita, gobernada por "una classe vestida a la moda i que no s'aturava per res" y habitada por "els desvagats presoners de la desesperació de la indiferència" (Palol 1996: 49-50). La venida del apocalipsis, por lo tanto, no se presentará como un acontecimiento súbito e inesperado sino, más bien, como el desarrollo necesario y consecuente de un proceso de autodestrucción ya encaminado, estadio último de una progresiva disgregación.

Tal como observa Julià Guillamon, una buena parte de los hechos relatados en el primer libro del Jardí, relativos a las vicisitudes del Banco Mir y de sus dirigentes, se sitúan en los primeros años de la década de los setenta y en la época de la transición española (Guillamon 2001: 127). Es decir, estamos alrededor de una frontera, de un momento histórico que la mayoría de los estudios más recientes sobre la ciudad considera clave para entender su conformación actual.

En uno de sus textos más conocidos -The Condition of Postmodernity, de 1990-, el geógrafo político de inspiración marxista 
David Harvey analiza el cambio socio-económico experimentado a principios de los años setenta por las sociedades capitalistas occidentales y busca sus lazos de unión con un cambio cultural que identifica con el comienzo de la posmodernidad. De acuerdo con el autor, como consecuencia de la primera crisis del petróleo, que inaugura la primera gran recesión de posguerra (estamos entre 1972 y 1975), se produce un cambio cualitativo en la configuración del poder económico-político del capitalismo tardío, que pasa de una fase fordista-keynesiana a un régimen de acumulación que define "flexible" y que está marcado por el comienzo de las políticas de desregulación financiera. Si la primera fase se caracteriza, simplificando mucho, por un importante control estatal y cierta rigidez y estabilidad estructural; el régimen de acumulación flexible busca eludir todo control colectivo y recurre al capital financiero como poder coordinador.

Flexible accumulation, as I shall tentatively call it, is marked by a direct confrontation with the rigidities of Fordism. It rests on flexibility with respect to labour processes, labour markets, products, and patterns of consumption. It is characterized by the emergence of entirely new sectors of production, new ways of providing financial services, new markets, and, above all, greatly intensified rates of commercial, technological and organizational innovation. (Harvey 1992: 147)

Desde el punto de vista del espacio urbano, las transformaciones estructurales del tardocapitalismo conllevan, necesariamente, una profunda metamorfosis de la ciudad y de la vida urbana. El año 1972 -año que David Harvey ( $y$, con él, autores como Manuel Castells, Henri Lefebvre, Edward Soja o Giandomenico Amendola) establece como fecha de inicio del cambio socioeconómico- es especialmente significativo para la vida y las representaciones de la ciudad occidental. Tal como observa Leonardo Lippolis en Viaggio al termine della città, en 1972 el proyecto urbanístico Pruitt-Igoe, diseñado y construido por Yamasaki en la periferia de St. Louis (Missouri) y considerado el símbolo del fracaso social de la arquitectura modernista, es dinamitado por el gobierno federal y bajo petición de los propios habitantes. Como es sabido, la demolición del edificio, puesta en marcha tan solo quince años después de su construcción, se considera, casi unánimemente, el momento de inicio de la arquitectura posmoderna, cuyo manifiesto teórico -Learning from Las Vegas, de Robert Venturi, Denise Scott Brown y Steven Izenour- se publicará en el mismo año. En 1972, Guy Debord publica $L a$ véritable scission dans l'Internationale Situationniste, texto con el cual sentencia la disolución de la Internacional Situacionista y la creciente dificultad de todas aquellas 
prácticas (derivas, paseos surrealistas, psicogeografía, crítica de la ciudad) que buscaban subvertir (o, más bien, pervertir) las normas impuestas por el capital a la vida cotidiana y, por lo tanto, a la organización urbanística: "produrre, riposare-consumare, abitare e circolare in modo rapido" (Lippolis 2009: 14) ${ }^{5}$. En 1972, Italo Calvino publica Le città invisibili, un "ultimo poema d'amore alle città, scritto nel momento in cui diventa sempre più difficile viverle come città" (Calvino 2013: IX).

Ampliamente conocidos, los rasgos de la ciudad que nacerá tras la reordenación económica del sistema tardocapitalista son compartidos por la gran mayoría de los investigadores. Multiétnica y fagocitante, la ciudad posmoderna -la "postmetropolis" de Edward Soja (Soja 2000) o la "soft city" de Jonathan Raban (Harvey 1992: 3)- se define por el reforzamiento de los dispositivos de control y seguridad, la fragmentación del cuerpo social y el aumento de las desigualdades socio-económicas, la proliferación de no-lugares y lugares virtuales ${ }^{6}$, la desaparición de los espacios y las categorías industriales $y$, más en general, la adecuación de la organización urbanística a las exigencias de la sociedad del espectáculo y del consumo masivo.

En la ciutat postmoderna, el que manté unida la ciutat no és cap límit físic ni tampoc la memòria, sinó el fluxos econòmics, les funcions d'atracció dels mercats de treball i de consum. La ciutat és l'espai de I'homo economicus, un conjunt de mercats de treball, d'intercanvi d'informació, regulats por la burocràcia administrativa. (Guillamon 2001: 233)

Sus calles son las calles que, entre principios de los años setenta y mediados de los ochenta, recorren -tal como hemos visto en los párrafos antes citados- los personajes del Jardí dels Set

\footnotetext{
${ }^{5}$ Normas establecidas por la Charte d'Athènes de Le Corbusier, redactada en el año 1933 y manifiesto de la arquitectura moderna.

6 Como es ampliamente sabido, el concepto de no-lugar remite a las investigaciones del antropólogo francés Marc Augé y, en especial modo, al ensayo de 1992 titulado Los "no lugares". Espacios del anonimato. Una antropología de la sobremodernidad. En él, el autor reúne bajo el nombre de no-lugar "tanto las instalaciones necesarias para la circulación acelerada de personas y bienes (vías rápidas, empalmes de rutas, aeropuertos) como los medios de transporte mismos o los grandes centros comerciales, o también los campos de tránsito prolongado donde se estacionan los refugiados del planeta" (Augé 1993: 41). Es importante subrayar que la expresión con la que titulamos el presente artículo -la no-ciudad posmoderna- no alude directamente a la teoría de Marc Augé, sino, de forma más general, al tema que nos atañe: el progresivo empobrecimiento del espacio urbano entendido como espacio de, y para, la vida pública en el régimen de acumulación flexible. Evidentemente, la proliferación de no-lugares en las ciudades posmodernas - descrita y analizada por el autor francés- se enmarca en este mismo proceso.
} 
Crepuscles. Removida por un insensato y caótico proceso de dinero fácil, la Barcelona de Miquel de Palol está experimentando una transición hacia la ciudad posmoderna; transición que Patrici Ficinus y Alexis Cros -"la generació que ha viscut les utopies dels seixanta" (Guillamon 2001: 127)- perciben como una disgregación y una pérdida, primer paso hacia el definitivo derrumbe. Como en las distopías analizadas por el crítico italiano Francesco Muzzioli en Scritture della catastrofe (Muzzioli 2007), también en la novela de Palol la llamada destrucción creativa, el mantra de los ideólogos de la ciudad neoliberal ${ }^{7}$, revela su poder aniquilador, y la reestructuración postfordista de los años setenta se presenta en forma de apocalipsis nuclear:

El meu mal no volia soroll, i vaig saltar d'un passatge sobre la deambulació de les voluntats al record de la meva ciutat [...]. La vaig veure amb els colors agres d'un malson, com si pels carrers hagués passat, successivament i sense pausa entre un deliri i l'altre, el més fuetejat dels incendis i la més tronadora inundació. Les voreres les havia tapades un riu de fang ja assecat. El centre dels carrers era intransitable per les roderes i els munts de runa. Les cases, ennegrides i descrostades, mostraven impúdicament els portals esventrats, amb acumulacions capricioses i brutals dels objectes més diversos, i mantenien molt poques finestres amb llum, i, encara, solia consistir en el tremolor sanguini d'un foc de luxe en destrucció [...]. L'aire era un udol d'amenaça aquàtica, més viu que un animal salvatge, i la llum tenia la terrosa ambigüitat del crepuscle; no es sabia de quin, si l'alba o la post, o d'un insòlit, desconegut, fill irrepetible d'aquella tromba retrunyent d'exsanguació. (Palol 1996: 706)

7 Para una crítica del concepto de "destrucción creativa" -desarrollado por el economista Joseph Schumpeter para indicar el proceso a través del cual nuevos productos, empresas o valores desplazan los existentes en el mercado, favoreciendo de tal forma un modelo (económico, pero también urbanístico) basado en la innovación, la reestructuración y el movimiento constantes- remito, una vez más, a los estudios de David Harvey. "Surplus absorption through urban transformation has an even darker aspect. It has entailed repeated bouts of urban restructuring through 'creative destruction', which nearly always has a class dimension since it is the poor, the underprivileged and those marginalized from political power that suffer first and foremost from this process" (Harvey 2008: 33). 


\section{De la ciudad postapocalíptica a la no-ciudad posmoderna}

De todas las características de la ciudad posmoderna mencionadas en el epígrafe anterior, conviene ahora recordar y desarrollar una en concreto, necesaria para dar un paso más en el análisis textual. Tal y como subrayan todos los investigadores citados hasta aquí, la recomposición de la forma urbana y de sus estructuras sociales tras la reestructuración económica postfordista se organizó en función de una exigencia ya universalmente compartida, de un nuevo deber civil: consumir. En palabras de Giandomenico Amendola, "la centralità urbana è sempre più segnata e definita dal consumo, così come organizzati intorno al consumo sono i frammenti di centralità diffusa della città diffusa" (Amendola 2009: XIV). Naturalmente, el planteamiento no es nuevo: como hemos visto, estaba ya presente en la Charte d'Athènes de Le Corbusier e incluso antes hervía en el París de los Pasajes benjaminianos. Después de 1972, sin embargo, se naturaliza y se convierte en ideología dominante:

[...] consumare è un imperativo che si allarga dall'ambito economico ed edonistico a quello etico. Comprare [...] è un dovere verso gli altri e la collettività. Fare shopping è virtù civile. Chi non consuma e non compra danneggia tutti. (Amendola 2009: XV)

Las consecuencias sobre la configuración urbana, numerosas y complejas, se pueden esquematizar focalizando la atención sobre tres elementos distintos: el suelo, la calle y la plaza; es decir, y adoptando categorías propias de la ciudad tradicional: el terreno objeto de compraventa, las vías de comunicación e interconexión y los lugares de estar, destinados al encuentro de personas $y$, en el caso de las plazas de mercado, al intercambio de mercancías. Si, por un lado, el sector inmobiliario se afirma como uno de los principales factores de dinamización de la economía (impulsando la frenética producción de un espacio que no es nada más que mercancía), las calles se convierten en los escaparates de un objeto -la propia ciudad- que ansía ser consumido: "strade, facciate, vetrine, insegne si saldano senza soluzione di continuità creando uno spazio quasi onirico scandito da stimoli, promesse e offerte" (Amendola 2009: $\mathrm{XV}$ ). En la ciudad posmoderna, además, las funciones tradicionalmente atribuidas a la plaza pública -intercambio, socialización, encuentro (y choque) de diferencias- se desplazan hacia los espacios del consumo (esencialmente, centros comerciales y corporate plaza) y hacia los llamados single-minded spaces (como, por ejemplo, los espacios comunes de las urbanizaciones cerradas 0 
de los complejos residenciales); es decir, espacios privados 0 destinados a intereses privados ${ }^{8}$.

Tal y como observa David Harvey en Consciousness and the Urban Experience, el resultado de estos procesos es la pulverización del espacio por parte de la propiedad privada y su segmentación en espacios homogéneos y controlados (Harvey 1985: 34). Producir espacios monofuncionales y cada vez más uniformes -comenta Giandomenico Amendola- conlleva "un reale impoverimento della città $\mathrm{o}$, quantomeno, una sua trasformazione profonda in qualcosa che, per il dominio assoluto del privato, ha ben poco della città classica o dell'urbanity" (Amendola 2009: 178). En la ciudad posmoderna, el capital fagocita al espacio público, entendido como espacio de, y para, la vida pública, colectiva y, por lo tanto, política. La ciudad posmoderna es una ciudad privada; es decir, un hábitat en el que el ciudadano se ve privado del acceso a la participación ciudadana y a una esfera pública cada vez más debilitada.

En la novela de Miquel de Palol asistimos a un fenómeno análogo. En los relatos que cubren el intervalo de tiempo que transcurre entre el regreso de Ficinus y Alexis Cros a Barcelona y el estallido del conflicto nuclear (es decir, entre los años ochenta y el año 2025), la ciudad no se vuelve a mencionar, el espacio urbano desaparece de las experiencias de los personajes-narradores. Con la sola excepción de los párrafos antes citados, los hechos transcurren en espacios privados, cerrados y homogéneos. Entre la ciudad en decadencia y la ciudad postapocalíptica, prospera la no-ciudad posmoderna: suma de espacios privados, ciudad invisible.

En ella, viven personajes como Robert Colom, Gertrudis, Randolph Carter o el propio narrador principal: es decir, las generaciones sucesivas a la de Ficinus y Alexis Cros, huérfanas de las grandes narraciones y de las utopías revolucionarias y entregadas a la búsqueda de intereses, principios y placeres individuales:

Havíem arribat a un temps que cadascú es fabricava la seva consciència (d'això mai m'atreviria a dir-ne moral), prenent una mica d'aquí i una mica d'allà, eliminant, retocant (i sovint oblidant i fent malbé) i adaptant a la mesura del seu gust i les seves necessitats, i a cop de disputes, supèrbia i usura mental, desenganys i malguanys, tota aquesta sopa nauseabunda que per no morir-te de riure n'acabes dient l'experiència [...]. Em va semblar que la generació anterior (la meva ja s'ho va trobar) havia fet el negoci d'en Robert i les cabres. Abans, durant els grans moviments de la fe $[\ldots]$, i encara durant les

${ }^{8}$ Con la expresión single-minded space, el filósofo y teórico político estadounidense Michael Walzer se refería a todos aquellos espacios creados para un solo tipo de destinatario; espacios monofuncionales que constituyen la negación de un espacio público (por definición, destinado a más usuarios y funciones) y que representan una evolución de la utopía burguesa del suburbio (vid. Amendola 2009: 178). 
seves conseqüències remotes, poca gent tenia necessitat d'arreglarse el món a seu gust, cosa que, a més, es considerava una bogeria socialment perillosa [...]. (Palol 1996: 713-714)

Habitantes de la no-ciudad posmoderna, prefieren la indiferencia al compromiso ideológico, la economía a la política, el individualismo a los proyectos colectivos". "Els déus havien desaparegut; era ociós buscar consol fora d'un mateix" (Palol 1996: 281). El espacio público tal como lo entendían Ficinus y Alexis Cros el lugar que posibilita el acceso a la esfera pública y a la acción política- se convierte en un sistema de obligaciones, en "una immensa bossa de pus" (Palol 1996: 3) que limita las libertades individuales y la iniciativa privada.

\section{Otros espacios, espacios privados: el jardín y el palacio}

Contrapuestos al ámbito urbano y a la progresiva desaparición de la esfera pública, el jardín y el palacio se afirman como los dos espacios más significativos de la novela, tanto desde el punto de vista narrativo como simbólico.

El Palau de la Muntanya -un refugio nuclear "d'ultima privacitat" (Palol 1996: XIII), probablemente situado en los Pirineos catalanesse presenta desde las primeras páginas como un centro de poder y privilegio. Tal como observa Guillamon (2001: 126), el imponente edificio de estilo neoclásico es un depósito de obras de arte y tecnologías del pasado: cráteras y lekitos del siglo $\mathrm{V}$ antes de Cristo, pedestales de mármol de Paros, bronces helenísticos, libros antiguos, astrolabios, cinematógrafos, pinturas de todas las épocas. En él, cada elemento funciona como símbolo de estatus y contribuye a crear una atmósfera onírica, bastante lejana de la Barcelona descrita unas pocas páginas antes:

L'interior de l'edifici contrastava com el dia de la nit amb l'extrema severitat de l'aparença externa. Ens van dur cadascú a la seva cambra, a través de la galeria que envoltava un altre pati, aquest descobert i amb un bellíssim paviment de tessel-les de tots colores; les parets del passadís eren estucades a la romana, amb motius florals i ocells, i profusament il-luminades. La meva habitació era fascinant. Un finestral amb balcó a ponent oferia un espectacle titànic de muntanyes nevades i cel estrellat. El llit de caoba i xicranda tenia dimensions italianes. Hi havia un tresillo de pell, i el luxe en tot allò que el tacte abastava només estava condicionat pel gust i la

\footnotetext{
9 "No hi ha dilema entre elecció ideològica i indiferència -deia Ferret-, perquè en un món de crèdits i propietats diluïdes, i desapareguda la classe obrera, la pugna de les ideologies s'ha substituït per la dialèctica entre les institucions de l'estat i la iniciativa privada, cada cop amb més desequilibri a favor de l'última" (Palol 1996: 676).
} 
comoditat. [...] El terra emmoquetat i càlid convidava a anar descalç, i la il-luminació era poderosa però indirecta; cap estridència no feria els sentits. (Palol 1996: 11, cursiva de la autora)

Mientras que el lujo y el refinamiento del interior del palacio buscan contraponerse a una Barcelona dejada "en mans dels estrangers, de la gent sense recursos [es decir, de los pobres] i dels desesperats" (Palol 1996: 3), el borgiano Jardí dels Set Crepuscles que da título a la novela- contrasta con el caos y el desorden de la realidad exterior. Reproducción del tópico del locus amoenus y del motivo boccacciano del jardín murado como símbolo de una existencia segura y apartada, el jardín de Palol es un espacio cargado de claras connotaciones neoplatónicas, en el que la disposición ordenada y armónica de los elementos (árboles, fuentes y piedras) esconde un mensaje en clave, un lenguaje secreto que solo la nueva élite podrá descifrar.

Vaig passejar-me pel Jardí del Crepuscle. [...] Les distàncies entre els
arbres eren considerables, com si s'hagués volgut que cap d'ells no
tapés la perspectiva d'un altre. Al mig del jardí n'hi havia tres en
filera, amb poc més de quinze metres entre ells. [...] Vaig acostar-me
a la barana per contemplar l'edificació. Des de dalt, la seva estructura
i la seva raó de ser eren evidents. Es veia perfectament com la
distribució, que des de dins podia semblar arbitrària, responia a una
perfecta coronació del terreny. (Palol $1996: 30$ )

Ambos espacios, por lo tanto, cumplen una doble función narrativa: por un lado, al representar el espacio de la huida y del refugio, marcan una distancia física, tangible, con la Barcelona postapocalíptica; por otro lado, marcan una distancia simbólica ya que conforman, en relación con ella, un sistema de oposiciones binarias (miseria vs. opulencia, destrucción vs. re-creación, caos vs. orden) en el que la mansión (es decir, el espacio privado) representa el polo positivo y la ciudad, el polo negativo. Ambos, además, se presentan como espacios narcotizantes, capaces de entorpecer la conciencia y la sensibilidad de los narradores: "el refugi en la mansió salvava els seus habitants amb un aire de vacances que condormia fràgilment els aspectes més conflictius del moment" (Palol 1996: 188). 


\section{A modo de conclusión}

La sociedad posindustrial -escribe Italo Calvino en su introducción a Una pietra sopra- "si manifesta come collasso, come frana, come cancrena (o, nelle sue apparenze meno catastrofiche, come vita alla giornata); e la letteratura sopravvive dispersa nelle crepe e nelle sconnessure" (Calvino 1980: 8). Tal y como hemos ido ilustrando hasta aquí, los textos literarios contemporáneos nos brindan la ocasión, por un lado, de reflexionar acerca de las transformaciones sociales e ideológicas que remueven nuestro tiempo y, por otro lado, de estudiar las estrategias con las que la propia ficción asimila, representa y analiza dichas transformaciones. El surgimiento de la ciudad posmoderna en el marco de la transición hacia el modo de acumulación postfordista se presenta, en la novela de Miquel de Palol, esencialmente de dos maneras. El empobrecimiento de la esfera pública y la desarticulación comunitaria (características destacadas por autores como Henri Lefebvre, David Harvey o Giandomenico Amendola) genera una dialéctica de presencia-ausencia: la ciudad como metonimia del espacio público, cívico y político desaparece de las páginas de la novela y de la memoria de los personajes, cuyas experiencias se enmarcan principalmente en espacios privados y privilegiados. Además, la propia transición al modo de acumulación flexible se presenta como un proceso de decadencia y de pérdida que tendrá, con respecto al espacio urbano, consecuencias aniquiladoras. Sobre la ciudad -parece sugerir el título del libro- ha caído la noche. Lo que ahora nos queda es seguir la invitación de Calvino: buscar en las grietas y en las fisuras lo que ha sobrevivido y darle espacio.

\section{Bibliografía}

AMENDOLA, Giandomenico (2009): La città postmoderna. Magie e paure della metropoli contemporanea. Primera edición: 1997. Roma-Bari: Laterza.

AUGÉ, Marc (1993): Los "no lugares". Espacios del anonimato. Una antropología de la sobremodernidad. Primera edición: 1992. Barcelona: Gedisa.

BENJAMIN, Walter (2005): Libro de los Pasajes. Edición de Rolf Tiedemann. Primera edición: 1982. Madrid: Akal.

CALVINO, Italo (1980): Una pietra sopra. Turín: Einaudi.

CALVINO, Italo (2013): Le città invisibili. Primera edición: 1972. Milán: Oscar Mondadori.

DÄLLENBACH, Lucien (1991): El relato especular. Madrid: Visor.

DEBORD, Guy; y SANGUINETTI, Gianfranco (1998): La Véritable scission dans I'Internationale. Circulaire publique de I'Internationale Situationniste. Primera edición: 1972. París: Arthème Fayard.

GARCÍA GALIANO, Ángel (2004): El fin de la sospecha. Calas significativas en la narrativa española (1993-2003). Málaga: Servicio de Publicaciones y Divulgación Científica de la Universidad de Málaga. 
GUILLAMON, Julià (2001): La ciutat interrompuda. Barcelona: La Malagrana.

HARVEY, David (1985): Consciousness and the Urban Experience. Oxford: John Hopkins University Press.

HARVEY, David (1992): The Condition of Postmodernity: An Enquiry into the Origins of Cultural Change. Primera edición: 1990. Oxford: Blackwell Publishers.

HARVEY, David (2008): "The Right to the City". New Left Review, vol. 53, pp. 23-40.

JAMESON, Fredric (2002): The Political Unconscious. Narrative as a social symbolic act. Primera edición: 1981. Londres: Routledge.

LE CORBUSIER (1933): La Charte d'Athènes [en línea]. En: http://wwwetsav.upc.es/personals/monclus/cursos/CartaAtenas.htm [Consulta: 14/09/2015].

LIPPOLIS, Leonardo (2009): Viaggio al termine della città. La metropoli e le arti nell'autunno postmoderno (1972-2001). Milano: Elèuthera.

MARRUGAT, Jordi (2014): Narrativa catalana de la postmodernitat. Barcelona: Ube.

MUZZIOLI, Francesco (2007): Scritture della catastrofe. Roma: Meltemi.

PALOL, Miquel de (1996): El Jardí dels Set Crepuscles. Primera edición: 1989. Barcelona: Proa. (Versión cast. El jardín de los siete crepúsculos. Madrid: Anagrama, 2007).

SOJA, Edward (2000): Postmetropolis, Critical Studies of Cities and Regions. Oxford: Blackwell Publishers.

VENTURI, Robert; Scott Brown, Denise; y Izenour, Steven (1972): Learning from Las Vegas: the Forgotten Symbolism of Architectural Forms. Cambridge: MIT Press. 